\title{
TRANSFORMAÇÕES DO CAPITALISMO CONTEMPORÂNEO: A RECONFIGURAÇÃO DE UM NOVO PADRÃO DE ACUMULAÇÃO CAPITALISTA
}

\author{
Victor Emmanuel Feitosa Hortencio \\ Doutorando do Programa de Pós-Graduação em Economia da Universidade Federal da Bahia \\ (PPGE-UFBA). Bahia, BA, Brasil. \\ victor.vefh@gmail.com \\ Ana Maria Rita Milani \\ Doutora do Programa de Pós-graduação em Economia, \\ Universidade Federal do Rio Grande do Sul. \\ Professora adjunta da Universidade Federal de Alagoas. Maceió, AL, Brasil. \\ anamilani16@hotmail.com
}

\begin{abstract}
Resumo - O presente trabalho tem o intuito de analisar os condicionantes históricos que marcaram o período de transição entre o antigo modo de acumulação capitalista, baseado no "fordismokeynesianismo" e o modelo atual, predominantemente financeiro. Destaca-se, também, os desdobramentos e as consequências dessa transição dentro das economias nacionais, centrais e periféricas, ena própria dinâmica de funcionamento da economia internacional. Para tal fim, se faz uma análise dos principais fatos históricos que cerceiam o ápice, e a derrocada do antigo padrão de acumulação capitalista, destacando os países responsáveis pelos (des)caminhos e ações que determinaram os rumos tomados pela história econômica do capitalismo contemporâneo.
\end{abstract}

Palavras-chave: Capitalismo; Padrão de Acumulação; Fordismo - Keynesianismo; Financeirização; Globalização.

\section{TRANSFORMATIONS OF CONTEMPORARY CAPITALISM: THE RECONFIGURATION OF A NEW PATTERN OF CAPITALIST ACCUMULATION}

\begin{abstract}
The presente paper aims to analyze the main historical events that marked the transition period between the old mode of capitalist accumulation, based on "FordismKeynesianism" and the current, predominantly financial mode. It also highlights the deployments and consequences of this transition within national, central and peripheral economies, and the dynamics of the functioning of the international economy. To this end, an analysis is made of the main historical facts that marked the apex and the collapse of the old pattern of capitalist accumulation, highlighting the countries responsible for the (dis) ways and actions that determined the directions taken by the economic history of contemporary capitalismo.
\end{abstract}

Key Words: Capitalism; Accumulation Pattern; Fordism - Keynesianism; Financialization; Globalization.

\section{INTRODUÇÃO}

Este trabalho parte da tentativa de reconstruir sinteticamente uma contextualização internacional dos fatos que marcaram o fim dos "Anos Dourados" do capitalismo contemporâneo, caracterizado como ponto de restruturação do modelo "keynesianofordista" de acumulação. Mesmo período em que se apresenta uma nova roupagem no funcionamento da economia internacional, que abriu espaço para uma alternativa de acumulação que se baseia na valorização da riqueza financeira, na qual o funcionamento 
dos sistemas financeiros nacional e internacional passou a influenciar a dinâmica da macroeconomia mundial da renda e do emprego (PINTO, 2011).

Assim, historicamente, em meio aos escombros da Segunda Guerra mundial, se erguiam novas formas de estruturação da economia internacional- institucionais e reguladoras-, edificadas, principalmente, no surgimento de uma nova ordem econômica mundial e na ascensão de uma poderosa hegemonia,dominante até os dias atuais.

As novas formas de poder e controle, foram legitimadas e tiveram uma potencialização de seu raio de dominação a partir da disseminação da ideologia liberal, personificada, principalmente, na globalização, iniciada mais intensamente no final dos anos 1970.

Como alternativa teóricaaos argumentos da "economia vulgar", que defendem o equilíbrio e os mercados autorregulados, tem-se a economia política, que tem o objetivo de aprofundar a análise dos fenômenos econômicos aparentes ${ }^{1}$, elucidandoas assimetrias, a inconstância e as crisesda dinâmica de distribuição e acumulação de riqueza, bem como, de entender a estrutura das relações sociais de produção subjacente à circulação de mercadorias na economia mundial (FIORI, 1997). Logo, é a partir dalógica da economia política internacional que toda a argumentação desse artigo é desenvolvida.

O presente artigo está estruturado em três partes centrais: a primeira trata sobre a derrocada do padrão ouro e a ascensão do padrão ouro-dólar, alicerçados na consolidação dos Acordos de Bretton Woods e no início do ciclo virtuoso da economia internacional no pósGuerra; a segunda parte discorre sobre a contestação da hegemonia americana e de como o jogo de poder se reafirmou após o "choque Volcker";a terceira mostra as consequências danosas, nas economias centrais e periféricas, da expansão da globalização e da financeirizaçãona economia mundial contemporânea. E por fim, são apresentadas as considerações finais.

\section{BRETTON WOODS E OS "ANOS DOURADOS": O "COMPROMISSO KEYNESIANO-FORDISTA"}

Junto com a decadência da hegemonia britânica ${ }^{2}$, no epílogo da Primeira Guerra, chegava-se ao fim do padrão ouro, que até então determinava as regras de criação e circulação monetária em nível internacional.Nesse período, a emissão das moedas nacionais e a taxa de câmbio estavam lastreadas ao estoque de ouro, e tinham livre conversão nesse metal nas transações internacionais. Com esse plano de fundo, de ausência de uma hegemonia clara,

\footnotetext{
${ }^{1}$ Buscando a descrição histórica e a essência dos fenômenos econômicos e sociais.

${ }^{2} \mathrm{Na}$ verdade, o que existiu até esse período foi um padrão libra-ouro, consubstanciado pela hegemonia britânica nos setores industrial, financeiro, comercial e político-militar (DATHEIN, 2005).
} 
criava-se as condições para a ascensão de uma nova potência mundial, estabelecidasomente mais tarde, em 1944 (DATHEIN, 2005).

Entre os anos 1942 e 1944, ocorreu em Bretton Woods, nos Estados Unidos, uma série de encontros e reuniões que visavam a consolidação de uma nova ordem mundial estável. Os objetivos centrais desses encontros, segundo Mello (2012, p.12), baseavam-se na reestruturação de um regime monetário unitário que, "num ambiente de livre desenvolvimento do comércio internacional, garantisse a confiança na moeda de referência, sem, todavia, a rigidez cerceadora do antigo padrão-ouro", a partir de mecanismos eficientes que assegurassem a liquidez necessária para o crescimento industrial e econômico dentro da nova conjuntura mundial.

O novo sistema monetário internacional surgia como uma solução para o histórico de experiências traumáticas vivenciadas pelos países centrais no período anterior. A repressão ao comércio mundial, a hiperinflação, o desemprego em massa, os movimentos especulativos vinculado aos mercados financeiros, a guerra e a depressão dos anos 1930, deixaram marcas profundas que careciam de um "remédio"que trouxesse um novo panorama de estabilidade para a economia mundial. Por outro lado, o período de crise financeira e as duas guerras mundiais cumpriram a função, não deliberada,de eliminar ou destruir grandes quantidades de capitais obsoletos, e de baratear os meios de produção, principalmente o trabalho, num contexto de desemprego em alta, criando, por conseguinte, uma grande oportunidade de concentração e centralização de capital (MELLO, 2012).

Somado à esses condicionantes, havia a urgência da reconstrução dos países centrais arrasados durante a guerra, caracterizando um imenso mercado potencial, aliado ao estoque de inovações tecnológicas -principalmente norte-americano- e organizacionais elaboradas desde o final do século XIX, até entãoainda pouco aproveitadas, que serviriam de referência de modernidade para os outros países avançados (MELLO, 2012; FRANJZYLBER, 1983).

A conferência de Bretton Woods teve como ponto central a criação de instituições - FMI e Banco Mundial ${ }^{3}$ - e normas que iriam gerir eregular o sistemaeconômico mundial nas próximas quasetrês décadas seguintes (DATHEIN, 2005). Sob sua vigência, houve determinações de liberalização do comércio internacional e de padronização monetária,estabelecendoa fixação das moedas em dólar, que por sua vez, poderiam ser trocadas por ouro. Todos esses "acordos" passaram a funcionar sob a tutela dos EUA, em virtude de sua posição de superioridade perante às outras economias centrais no pós-Guerra (BALANCO \& PINTO, 2007).

Eichengreen (2000, p.131), acrescenta que esse novo sistema econômico-monetário configurou-se a partir de três elementos fundamentais:

\footnotetext{
${ }^{3}$ Fiori (1997), ressalta que essa foi um fator importante, junto com os acordos multilaterais, que marcam as diferenças entre o padrão ouro e o padrão dólar.
} 
[1] O câmbio tornou-se ajustável, sujeito a condições específicas (a saber, a existência do que era conhecido como "desequilíbrio fundamental"). [2]Aceitavamse controles de para limitar os fluxos de capital internacionais. [3] E uma nova instituição, o Fundo Monetário Internacional, foi criada para monitorar as políticas econômicas nacionais e oferecer financiamento para equilibrar os balanços de pagamento dos países em situação de risco.

A arquitetura e os principais mecanismos que constituíam o acordo de Bretton Woods tinham uma linha anticíclica e de pró-crescimento econômico que, internamente, primavam pela criação de um conjunto de políticas fiscais e monetárias que promovessem a acumulação de capital; no âmbito externo, restringiam os movimentos dos capitais especulativos predatórios, além de garantir liquidez e fomentar o comércio internacional (MELLO, 2012; DATHEIN, 2005).

Uma das questões problemáticas que Bretton Woods enfrentou foi a de garantir a liquidez internacional em moeda americana, ou seja, em dólares. Tendo em vista que a Europa tinha perdido substancialmente sua capacidade produtiva durante a guerra, representando uma limitação importante para a realização de exportações direcionadas aos EUA. A solução para este problema, porém, não totalmente eficiente, foi a criação do BIRD (Banco Mundial), que tinha a função de fornecer empréstimos -garantindo segurança e confiança, algo que não havia nos emprestadores privados - para a reconstrução da Europa.

Mesmo possuindo duas instituições financeiras importantes -FMI e BIRD ${ }^{4}$-, os EUA não conseguiam suprir a demanda de transferências e, consequentemente de liquidez, necessária para abastecer o mercado europeu devidamente.Então, mais três fatores foram de grande importância para se chegar a um nível suficiente de transferênciasinternacionais: i) a Guerra Fria com o Plano Marshall - através de empréstimos bilaterais e doações-;ii) a instalação de bases militares em soloeuropeu; e iii) a instalação de empresas multinacionais americanas na Europa (DATHEIN, 2005).

Assim, sob a égide dos acordos de Bretton Woods, trilhava-se um novo período da economia mundial, o "fordismo-keynesianismo", denominado por Franjzylber (1983),como um "novo ciclo virtuoso acumulativo".

Logo, as duas décadas e meia que se seguiram ao fim da Segunda Guerra Mundial foram marcadas por níveis impressionantes de acumulação de capital. Balanco\& Pinto (2007.p.38), ressaltam que a intensa acumulação de capital ocorrida nesse período foi respaldada pelas mudanças gestadas no núcleo funcional composto pelas grandes empresas, que aprofundaram seu raio de ação nacional e internacional, e pelo "Estado planejador/produtor mediante forte

\footnotetext{
${ }^{4}$ Segundo Dathein (2005), o Banco Mundial e o FMI não contavam como apoio da direita política no congresso dos EUA e dos banqueiros de Wall Street para essa empreitada.
} 
intervencionismo e "regulação". Os autores, de forma sistemática, defendem que se conformava uma nova macroeconomia socioeconômica capitalista, na qual prevalecia uma forte presença estatal em termos normativos e produtivos, diretamente articulados aos objetivos e ao pacto social voltado para o "estado de bem-estar social" ou WelfareState.Esta mudança relacionada ao comportamento e a "função" do Estado estava ligada à dois elementos basilares:

1] um inquestionável aparato de regulação com o propósito principal de enquadramento do capital financeiro e seu direcionamento para o financiamento da produção através do planejamento, considerado necessário à própria dinâmica do capital naquele momento histórico; e 2] uma acomodação das contradições entre capital e trabalho por meio de certas concessões, por parte do capital, aos trabalhadores dos países centrais (compromisso keynesiano-fordista ou estratégia de harmonização) e de forte coerção, por parte das ditaduras militares, dos frágeis movimentos operários dos países periféricos (BALANCO \& PINTO, 2007,p.35).

Por outro viés, o produtivo, Franjzylber (1983) analisa as transformações ocorridas nos "Anos Dourados". Considerando a indústria como o motor de crescimento capitalista naquele momento, o autor mostra que a taxa de crescimento industrial nas economias avançadas no período pós-Guerra praticamente dobra quando comparado à primeira metade do século XIX. Por exemplo, entre os anos 1900-1950, a produção cresceu a uma taxa média de 2,8\% a.a., enquanto nos anos 1950-1975, chegou a 6,8\% a.a. (FRANJZYLBER, 1983).

Nesse período de rápida expansão, o setor industrial não só muda sua dinâmica interna, como também, arrasta e modifica o restante das atividades produtivas: captando e atraindo mão de obra do setor agrícola, potencializando os insumos e os equipamentos para a sua modernização; gerando novas atividades no setor de serviços necessários para a produção, como o marketing, o financiamento de bens industriais; retroalimentado, portanto, a própria expansão industrial. Além disso, a própria base tecnológica da indústria era regularmente revolucionada, com a inserção de máquinas mais modernas e novos processos de produção entrando em funcionamento, resultando em saltos consideráveis na produtividade do trabalho (FRANJZYLBER, 1983; MACNALLY, 2010).

Paralelamente, se perfazia o deslocamento do consumo de bens não duráveis para o consumo de bens duráveis, que no Estados Unidos já tinha se tornado algo pujante no pósguerra, mas que depois se espalhou para as demais países avançados e emergentes, engendrando a necessidade de múltiplas atividades de serviços direcionadas à manutenção, distribuição, financiamento e publicidade, ou seja, um mercado auxiliar atrelado à indústria não menos importante que o principal.

\footnotetext{
${ }^{5}$ Fiori (1997.p.103) descreve esse período dizendo que "o embeddedliberalismde que já falou JhonRuggie, [foi] sustentado por uma política monetária e comercial complacente dohegemone viabilizado por um movimento sindical que manteve-se fiel ao pacto social implícito nas relações entre o capital e o trabalho".
} 
Segundo MacNally (2010), a economia mundial nunca havia visto um período de bonança como aquele. Por um quarto de século, as economias centrais cresciam, gerando emprego, lucros robustos e rendimentos crescentes. No transcurso de apenas vinte e cinco anos, a produção das economias desenvolvidas triplicou, condicionando uma melhora significativa no padrão de vida da massa assalariada, como consequência tanto do aumento real dos salários, quanto do incremento dos lucros ${ }^{6}$.

É nesse contexto que se consolida o "fordismo", que ultrapassando o sentido estrito de modelo de produção industrial, chega ao conceito amplo de representação de uma etapa determinada do desenvolvimento capitalista. Que de forma analítica, segundo Mello (2012, p.34), "corresponderia a um novo sistema de reprodução da força de trabalho, uma nova estética e uma nova psicologia, em suma, um tipo de sociedade democrática, racionalizada, moderna e populista". Totalmente associado ao processo de produção em massae ao seu próprio modo de consumo, trazendo consigo um complexo aparato institucional que ampara todo um modelo de reprodução, na qual se remete a uma estética específica, um conjunto de ideologias, de instituições, de costumes, de hábitos, de rotinas, que não diz respeito somente à dinâmica produtiva, como também às formas de organização laboral e estratificação social de dado momento histórico (MELLO, 2012).

\section{O “CHOQUE VOLCKER” E O NASCIMENTO DO NEOLIBERALISMO}

No intervalo entre os anos 1955 e 1973, se evidenciou um duplo movimento na economia internacional. Enquanto os Estados Unidos demonstravam dificuldades em manter o seu padrão de acumulação ${ }^{7}$, as economias da Europa Ocidental e o Japão começavam a assimilar o "sistema industrial americano", iniciando a partir daquele momento seu ciclo expansivo. Já nos anos 1960 os EUA davam mostras que seu longo período de expansão começava a se extinguir, essa situação se traduzia na diminuição de sua taxa de crescimento, no debilitamento de seu comércio exterior e de suas contas fiscais. No que se refere ao problema fiscal, segundo Tavares (1997), o déficit provinha da agressividade de suas próprias políticas financeira e armamentista.

Intensificando essa situação de crise, o número de pessoas oficialmente desempregadas nos principais países capitalistas saltou de oito para quinze milhões. Assim, os governos se

\footnotetext{
${ }^{6}$ Entre 1952 e 1973, a produção por trabalhador dobrou, ajudada esmagadoramente por inovações tecnológicas e novas máquinas. Os empregadores poderiam, portanto, aumentar os salários e ainda desfrutar de lucros crescentes, desde que as melhorias salariais ficassem aquém dos aumentos de produtividade (MACNALLY, 2010).

7 Tavares ressalta que "os EUA nunca tiveram uma política industrial explícita e de longo prazo, salvo no complexo militar. Assim, os esforços de inovação tecnológica e eletrônica seguiram a orientação "natural" do mercado militar e dos serviços bancários e de comunicações, destinados, ambos, a reforçar o poder internacional da potência dominante. Esses avanços tecnológicos, como se verificaria mais tarde, não melhoravam a competitividade nas indústrias de bens de consumo duráveis nem nos complexos metalmecânico e elétrico, aos quais estavam ligados, o "modelo taylorista-fordista", que havia sustentado a difusão do padrão industrial (americano) no pós-guerra, tornava-se rapidamente anacrônico, e a base interna de sustentação sistêmica de uma economia de produção e consumo de massas começa a ser erodida" (TAVARES, 1993, p.28).
} 
encontravam presos num círculo vicioso, na qual a perda de postos de trabalho e a redução da atividade econômica estavam acabando com as receitas fiscais no exato momento em que os gastos com assistência social aumentavam exponencialmente (MACNALLY, 2010).

Além do esgotamento do padrão de crescimento, os EUA passaram nessa mesma fase por delicadas situações internas e externas, que resultaram de forma conjunta na falsa crença de que a hegemonia americana estava chegando ao seu fim. Cano (2000) acrescenta que,

Com efeito, além das perdas econômicas já citadas, os EUA haviam sofrido, entre outros, os seguintes problemas: o tensionamento alto entre EUA, Cuba e URSS, entre 1959 e 1963, o assassinato do presidente Kennedy e Martin Luther King, a Guerr a do Vietnã, a vitória socialista no Chile e a declaração oficial da inconversibilidade do dólar em ouro em 1972 (CANO, 2000, p.23).

Segundo Cano (2000), os dois movimentos contrários, de esgotamento e auge, ocorridos naquele momento aceleraram a saída para o exterior de capitais produtivos e financeiros. Primeiro as filiais norte-americanas se direcionavam para o resto do mundo (principalmente para a Europa), depois os próprios capitais europeus e japoneses seguiram o mesmo caminho.

Tivemos, assim, um período de cerca de quinze anos em que tanto os imperialismos tinham interesse em conquistar ou expandir suas posições também em certas partes da periferia, quanto estas desejavam esses investimentos para poder prosseguir seus processos de industrialização, agora com a implantação de setores de maior complexidade, como material de transporte, equipamento, aparelhos elétricos, petroquímico etc. (CANO, 2000, p.22).

Esse plano de fundo de desequilíbrio financeiro e comercial nos EUA, somado a ajuda externa dada à Europa e ao Japão, mais os fluxos de capitais direcionados para o exterior, engendravam um movimento inicial de acumulação de créditos e excedentes financeiros em dólares, alocados em sua grande maioria na Europa, "constituindo o chamado euromercado de dólares, ponto de partida para o desenvolvimento da extraordinária "bola de neve" em que se constituiria o sistema financeiro internacional." (CANO, 2000.p.23).

A expansão do sistema financeiro internacional na década de 1970 é acelerada, como resultado da inflação do período vigente, como também pela reciclagem dos petrodólares acumulados pelos contínuos aumentos dos preços do petróleo entre os anos 1973 e $1979^{8}$. Nos primeiros anos da década de 1970 também ocorria o esgotamento do padrão de crescimento econômico visto após os anos 1950 na Europa e no Japão. Então, ao passo que acumulação produtiva baixava, os excedentes financeiros se multiplicavam debilitando o orçamento público da maioria dos países desenvolvidos, aumentando consideravelmente a dívida pública destes.

\footnotetext{
${ }^{8}$ A partir de 1976 se iniciou a "reciclagem" dos "petrodólares", esses capitais eram resultantes do aumento temporário do preço do petróleo, e que por sua vez eram aplicados em Londres pelos potentados do golfo Pérsico (CHESNAIS, 2005).
} 
Durante esse mesmo período, se davam os primeiros passos da relação "siamesa"9 entre Estados Unidos e China, resultado da investida estratégica norte-americana de retomar seu poder no âmbito do sistema mundial. Os vários condicionantes históricos daquele período enfraqueceram e "puseram em xeque" a soberania da potência capitalista ${ }^{10}$. Diante desse contexto, os EUA não ficaram indiferentes, e criaram uma estratégia política na tentativa de reverter essa situação, segundo Pinto (2011), entre várias medidas estava o processo de aproximação americana com a China comunista, no intuito de reduzir o avanço da URSS. O reestabelecimento das relações diplomáticas entre China e Estados Unidos ocorreu em janeiro de 1979, processo que gerou uma série de acordos bilaterais nas esferas científica, econômica e cultural. O autor descreve que,

[...] essa parceria estratégica, por um lado, criou uma das condições para o início do milagre econômico chinês: a inclusão da China ao mercado de bens e ao mercado de capitais dos Estados Unidos, que permitiu sua arrancada exportadora e ao acesso chinês ao financiamento internacional americano. Por outro lado, ela permitiu a maior e mais rápida expansão do território econômico supranacional americano, pois potencializou significativamente o poder do dólar e dos títulos da dívida pública do governo americano e a capacidade de multiplicação do seu capital financeiro (PINTO, 2011, p. 24).

O transcurso desse período também é marcado pelo alojamento do capital financeiro ocioso e abundante nos países subdesenvolvidos, endividando-os cada vez mais. Visto que, segundo Chesnais (2005, p. 39), a "reciclagem dos "petrodólares" tomou a forma de empréstimos e de abertura de linhas de crédito dos bancos internacionais aos governos do Terceiro Mundo, sobretudo da América Latina". A partir daí as bases da dívida dos países emergentes estavam lançadas, e com ela um mecanismo de transferência de recursos reprodutíveis no tempo. Pois, para autor, a dívida tende a se recriar sem cessar, observando que o nível das taxas de juros são superiores ao dos preços e às taxas da produção e do Produto Interno Bruto (PIB), aumentando o montante desses compromissos de forma célere, chamado de efeito "bola-de-neve da dívida". Assim,

Os juros devidos sobre o principal da dívida (o serviço da dívida) absorvem uma fração sempre maior do orçamento do Estado, das receitas das exportações e das reservas do país, de sorte que a única maneira de fazer face aos compromissos do serviço da dívida é tomar um novo empréstimo (CHENAIS, 2005, p.39).

$\mathrm{Na}$ retaguarda desse processo, ocorria o recrudescimento da crise econômica norteamericana, resultando consequentemente na fragilização da credibilidade do dólar como moeda hegemônica ${ }^{11}$, em 1971 os EUA também rompem unilateralmente com o sistema monetário de Bretton Woods. Tavares (1997), ressalta que o agravamento da crise do padrão dólar após 1968,

\footnotetext{
${ }^{9}$ A ascensão da economia chinesa na dinâmica macroeconômica mundial não criou uma competição agressiva com os EUA, pelo contrário, o que se configurou foi uma relação econômica complementar profunda, nos planos comercial, produtivo e financeiro, podendo ser chamada até de "concorrência amistosa" (PINTO, 2011).

${ }^{10}$ Pinto (2011) ressalta que a partir dos anos 1960 houve uma intensificação do conflito político entre os países capitalistas e socialistas, agravando ainda mais a contestação da supremacia americana no próprio polo capitalista.
} 
fez Londres cortar a conversibilidade da libra em dólar, libertando o mercado de crédito interbancário e de reservas dólar-ouro, estabelecendo assim o seu próprio circuito supranacional de crédito, com uma liquidez abundante e crescente, sem em contrapartida, qualquer relação com o déficit de balança de pagamento americano.

O cenário de contestação da força do dólar -"dólar fraco"- se inverte na Reunião mundial do FMI em 1979, quando Mr. Volcker, presidente do FED (Federal Reserve), declarou que não admitia mais a desvalorização do dólar, situação que se arrastava desde 1971 - principalmente em 1973. A partir desta reviravolta, ele subiu violentamente a taxa de juros interna ${ }^{12}$ e declarou que o dólar manteria sua situação de padrão internacional e que a hegemonia da moeda iria ser restaurada. Dessa forma,

\begin{abstract}
Com sua moeda contestada, os EUA não vacilaram e, em fins de 1979, aceleraram a elevação de suas taxas de juros, iniciando a política do "dólar forte", que iria até 1985. Essa ousada jogada, além de obviamente elevar a conta devedora de juros do governo americano, quebraria financeiramente a quase totalidade dos países devedores e praticamente obrigava o Japão e a Alemanha a financiarem os déficits americanos. Por outro lado, a valorização do dólar e a elevação das taxas de juros impuseram aos países desenvolvidos a desvalorização de suas moedas e uma séria recessão [1980-1983] (CANO, 2000, p.26)
\end{abstract}

A diplomacia do "dólar forte" custou caro, fez os EUA entrarem juntamente com a economia mundial numa recessão que durou três anos. A violenta recessão estrutural desencadeada pela política de elevação dos juros quebrou várias grandes empresas e muitos bancos americanos. Assim, além de levarem consigo vários países devedores, os EUA pararam com a farra industrializante na periferia, forçando os países capitalistas a entrarem num longo ajuste recessivo alinhado com as políticas americanas. "A bem da verdade, a política de reestruturação norte-americana foi feita à custa do neoliberalismo dos demais paises [...]" (CANO, 2000, p.26).

Macnally (2010), denomina esse momento de ofensiva americana como "o dia em que a músicaparou”.Chegava-se assim, ao fim dos “Anos dourados do Capitalismo”, no qual, jáse podia enxergar no horizonte os primórdios do neoliberalismo, que seria, no caso "a virada para um forma mais virulenta de capitalismo, que resultaria em uma nova onda de expansão embora com um padrão de crescimento baseado na crescente desigualdade social, aumento da pobreza global e aumento da insegurança humana” (MACNALLY, 2010. p.26).

\footnotetext{
${ }^{11}$ Pinto \&Balanco (2013, p. 6) ressaltam que "no fim da década de 1970, mais especificamente entre 1977 e 1978, o dólar apresentava sinais evidentes de sua fragilidade como unidade de valor em escala mundial em virtude da ameaça decorrente do fortalecimento do marco e do iene. As estratégias norte-americanas, ao longo dos anos 1970, de criação de déficits fiscais e em conta corrente cada vez mais elevados para garantir a expansão da competitividade do setor manufatureiro, em associação com a expansão dos euromercados, geraram uma forte desvalorização do dólar e o concomitante afloramento da situação nevrálgica de questionamento da própria posição desta divisa como moeda-chave internacional”.

${ }^{12}$ A "diplomacia dólar forte" foi uma decisão unilateral dos EUA que, com sua política de juros altos, promoveu valorizações da ordem de 50\%, entre 1980 e 1985 (TAVARES, 1993).
} 


\title{
GLOBALIZAÇÃO, FINANCEIRIZAÇÃO E ENDIVIDAMENTO
}

De acordo com Chesnais (2005), nos países subdesenvolvidos, a dívida tornou-se uma força perfeita que permitiu a viabilidade da imposição de políticas ditas de ajuste estrutural e a iniciação de processos de desindustrialização em muitos desses países. Essa condição de endividamento fortaleceu a antiga dominação econômica e política dos países centrais sobre os periféricos. Então,

Foi nos países do Terceiro Mundo, incentivados a se aproveitar dos créditos aparentemente vantajosos associados à reciclagem dos petrodólares, que as consequências do "golpe de 1979" foram mais dramáticas. A multiplicação por três e mesmo por quatro das taxas de juros, pelas quais as somas emprestadas deviam ser reembolsadas, precipitou a crise da dívida do Terceiro Mundo, cujo primeiro episódio foi a crise mexicana de 1982 (CHENAIS, 2005, p.40)

Por conseguinte, todos os países afetados pela empreitada americana se alinharam ao ideário liberal; a busca tanto por lugares receptivos para os capitais ociosos quanto pela eficiência desse mercado se chocava com o Estado nacional regulador e social de alguns países. Como resposta, várias medidas foram impostas, fundamentalmente: “i) ruptura dos monopólios públicos; ii) privatizações; iii) abertura comercial; iv) desregulamentação dos movimentos do capital internacional; v) flexibilização das relações trabalho/capital; e vi) cortes nos gastos sociais"(CANO, 2000.p.27).

Pinto \&Balanco (2013, p. 7) descrevem que durante os anos 1980,

\begin{abstract}
Mediante um enquadramento dos diversos países, tanto os capitalistas quanto aqueles que constituíam o bloco soviético, centrais ou periféricos, os EUA, a partir de 1985, buscaram adotar um estilo mais "pluralista" nas relações externas por meio de uma maior coordenação entre os países capitalistas centrais através das instituições "supranacionais" (FMI, Banco Mundial e Organização Mundial do Comércio), ou por intermédio de uma coordenação mais efetiva entre os bancos centrais do G-7 [Acordo de Plaza (1985) e do Louvre (1987)]. Cabe destacar que o Acordo de Plaza - desvalorização do dólar - abarcava a ofensiva comercial norteamericana sobre o Japão, resultando na adoção de uma política macroeconômica regional expansiva durante os anos 1980 e 1990 na Ásia.
\end{abstract}

Durante esse momento conturbado vivenciado nos anos 1980, todos os bancos internacionais se direcionaram para Nova York, não apenas sobre a proteção do FED, mas obrigatoriamente financiando o déficit fiscal americano. Neste caso, a dívida é o único instrumento que os EUA têm para realizar uma captação forçada da liquidez internacional. Sendo assim, apesar das críticas ao déficit americano, este se tornou na prática o único elemento de estabilidade temporária do mercado monetário e de crédito internacional. Mostrando que o preço desta "estabilidade" resultou na submissão dos países à diplomacia do dólar e o ajustamento progressivo de suas políticas econômicas pelo bem do "equilíbrio global do sistema" (TAVARES, 1997).

Na Europa, por sua vez, as eleições de Margaret Thatcher em 1979 e a de Helmuth Kohl, em 1982, representantes ilustres dos movimentosliberais-conservadores da Inglaterra e na 
Alemanha, respectivamente, respaldaram a retomada hegemônica americana, iniciando as "restaurações conservadoras" mais "extensas e radicais da história moderna, companheira inseparável da "revolução financeira global" liderada definitivamente pelas políticas de desregulação e deflação dos novos governos conservadores" (FIORI, 1997. P.115).

Em linhas gerais, o alinhamento ao ideário liberal e as políticas institucionais levaram a economia mundial a um reordenamento econômico de globalização financeira concentrada em Wall Street. Por conseguinte, a classe rentista relativamente controlada durante nos "anos dourados" renasceu, possibilitando a reafirmação do poder dos Estados Unidos como regulador desse capital.

Tavares (1997)destaca que, a partir daquele momento os EUA retomaram o crescimento. A autora descreveu em três pontos o transcorrer desse processo. O primeiro fato reconhece que a recuperação da economia americana foi feita com crédito de curto prazo e com endividamento crescente, copiando a técnica latino-americana (Brasil e México) dos anos 1970 e japonesa (usada nos anos 1950) de desenvolvimento: financiamento do crescimento com base em crédito de curto prazo; endividamento externo e déficit fiscal. Porém os EUA não foram castigados com os efeitos perversos da inflação, porque driblaram esses efeitos com sua moeda hegemônica e sobrevalorizada.

O segundo ponto diz respeito à influência da taxa de juros sobre o investimento. Salientando que os americanos não estão financiando o investimento através do mercado de capitais. Os EUA não tem mercado de capitais novos, o mercado de destaque hoje é o monetário ou o de crédito de curto prazo. Tavares (1997, p.39), argumenta que os EUA “estão substituindo o tradicional endividamento de longo prazo (através da emissão de debêntures, equities, etc.) por crédito de curto prazo ou utilizando recursos próprios e de capital de risco externo".

Já o terceiro ponto, fundamental no processo de restauração da posição hegemônica dos EUA, aparece quando se analisa as relações econômicas internacionais. Entre os anos de 1982 e 1984, os EUA conseguiram dobrar o seu déficit comercial a cada ano, absorvendo em contrapartida o recebimento de juros através de transferências reais de poupança do resto do mundo. Esse montante foi direcionado para a modernização da indústria de ponta americana, sem fazer qualquer esforço intensivo em poupança e investimento, sem tocar em qualquer área estrutural (energética, transportes e agricultura), os EUA melhoraram suas relações de troca e seus custos internos, baseados em importações baratas de equipamentos modernos e na entrada de capitais de empréstimo e de risco vindos de muitas partes do mundo (inclusive da periferia) (TAVARES, 1997).

Fora dos EUA, os anos 1980 foram marcados por articulações políticas e econômicas neoprotecionistas. Na Europa tentava-se consolidar o bloco CEE (Comunidade Econômica 
Europeia), como único meio de se protegerem da concorrência com o Japão e EUA, além de terem como objetivo o alinhamento dos passos germânicos com o pensamento europeu, já que a Alemanha estava adiantada em termos tecnológicos quando comparada ao resto do continente. De maneira que,

Na Ásia, o Japão vinha desde a década de 1960 construindo um bloco de fato, por meio de acordos, associações e participações, estreitando suas relações de comércio, de transferência de tecnologia, e de investimentos com os chamados NICs asiáticos. A retaliação norte-americana não se fez esperar: o tratado da NAFTA, de início com o Canadá e mais tarde incorporando o México, constituía o bloco norte-americano. Na verdade, e a despeito do discurso neoliberal, os três blocos constituem formas de neoprotecionismo (CANO, 2000, p.27).

Segundo Cano (2000), com a intensificação da concorrência imperialista vista nessa fase, o capital ocioso foi rapidamente posto a trabalhar, se direcionando a compra de propriedades e direitos públicos - acesso a monopólios e privatizações - ou por várias formas de ajustes interempresas, como por compra total ou parcial, cessão de direitos, participação e outros. Esse movimento internacional dos fluxos de investimento e os montantes negociados nos anos 1984-1989 configuram uma concentração privada de capital em níveis altíssimos nunca vistos até então.

Por conseguinte, as Empresas Transnacionais (ETs) aumentaram ainda mais sua capacidade de monopólio na concentração tecnológica, financeira, mercadológica, de comércio exterior e de investimentos, amparadas externamente nos seus correspondentes polos e Estados nacionais. Logo,

\begin{abstract}
Além dos investimentos em simples transferências de propriedade, as ETs intensificaram e aceleraram o uso de um conjunto de novas tecnologias - que comporiam a chamada Terceira Revolução Industrial - que começavam a dar seus primeiros passos comerciais: as de automação, de informatização, de novos materiais, de gestão administrativa, comercial e financeira. Desnecessário falar que para os países subdesenvolvidos seus efeitos são mais graves: sucateamento do capital físico e do trabalho, e substituição de insumos tradicionalmente produzidos pelos novos materiais (CANO, 2000, p.28).
\end{abstract}

Após o curto período de crescimento e restruturação (1984-1989), a acumulação produtiva se contraiu novamente em praticamente todos os países. Todavia, a acumulação financeira conseguiu seguir adiante, proporcionada pelas desregulamentações nacionais a favor do transito dos capitais financeiros, da globalização financeira e do movimento especulativo sem precedentes. Isto posto, só era necessário diminuir os riscos, ou seja, o chamado "risco país", para o estabelecimento dos fluxos financeiros nos países subdesenvolvidos. Então, os credores orquestrados pelos norte-americanos começaram as investidas no processo de renegociação das dívidas externas. Esses acordos visavam: "assinatura de acordos de garantia de investimentos, a lei de patentes e propriedade intelectual, e um "pacote" de reformas onde a privatização e o fim dos monopólios públicos", facilitando a abertura de espaço para a massiva entrada de capitais. 
Como resultado, os mercados "emergentes" ou subdesenvolvidos responderam a altura, propiciando gigantescos ganhos especulativos, inicialmente com os juros reais elevados e títulos, com privatizações realizadas a preços baixos e através especulações em bolsa de valores. Posteriormente uma grande parte dos capitais foi se direcionando para o setor de serviços, a especulação também se instalou em títulos imobiliários, originando bolhas nos valores desses ativos.

A década de 1990 é marcada com fim da União Soviética e da Guerra Fria. Como consequência, a retórica liberal estadunidense tomara corpo no cenário internacional, defendendo que a melhor forma de funcionamento do sistema econômico mundial seria sob a crença do "poder pacífico do mercado" e da "força econômica convergente da globalização" (PINTO \& BALANCO, 2013). Todavia, como conclui Pinto \&Balanco (2013, p. 8) "a suposta convergência econômica que surgiria do processo de liberalização econômica, patrocinado pelo EUA ao redor de boa parte do mundo não se materializou". Pelo contrário, o que se observou na década de 1990 foram práticas macroeconômicas mundiais distintas, com taxas de crescimentos díspares. Enquanto o EUA e parte do leste asiático cresceram com taxas consideráveis, os países da OCDE, da América Latina, da África e o Japão apresentaram taxas de crescimento pífias, ocorrendo em alguns casos, crises econômicas e financeiras séries e persistentes. Sendo assim,

\footnotetext{
O significativo crescimento econômico estadunidense, principalmente entre 1995 e 2000 , em que a taxa média anual de expansão do PIB foi superior a $4 \%$ ao ano, foi impulsionado pela elevação expressiva dos investimentos privados (superior a $8 \%$, em média, entre 1995-2000) e pelo consumo das famílias. Esses resultados se apoiaram em um novo arranjo produtivo-financeiro [...] (PINTO \& BALANCO, 2013, p. 8-9).
}

$\mathrm{Na}$ esfera produtiva, a ascensão da produtividade do trabalho e dos fatores foi baseada no processo de mudança tecnológica apoiada nas novas tecnologias da informação e da comunicação e, na esfera financeira o crescimento estava amparado numa "bolha" financeira permanente que alavancava os investimentos produtivos e o consumo privado. Esse novo contexto característico entre os anos 1990-2000 pode ser chamado de "regime de acumulação predominantemente financeira", pois, os setores financeiros foram os grandes responsáveis pela acumulação da riqueza em escala mundial ${ }^{13}$. Nessa sistemática de acumulação, tanto os proprietários do capital quanto os consumidores de alta renda, mostram dois elementos importantes "um [é o] "efeito-renda", que financia o consumo com base em dividendos e juros, $e$ [o outro é o efeito] "posse de patrimônio", que patrocina despesas apoiadas em antecipações de ganhos financeiros futuros" (PINTO \& BALANCO, 2013, p. 8-9).

Dessa forma, Fiori (2006),acrescenta que o antigo eixo dinâmico da economia mundial presente na década 1970, se desfaz, pois as economias alemã e japonesa não conseguiram

\footnotetext{
${ }^{13}$ Para mais informações ver Chesnais, 2005.
} 
acompanhar o ritmo de crescimento dos Estados Unidos, se deparando com um estado de letargia econômica crônica ${ }^{14}$. Simultaneamente,

[...] as economias nacionais do sudeste asiático, em particular da China e da Índia, transformaram-se na nova fronteira de expansão e de acumulação capitalista do sistema mundial, estabelecendo uma relação "virtuosa" - desde 2001 - de equilíbrio financeiro e de crescimento econômico com os Estados Unidos e com várias periferias ou subperiferias do sistema econômico mundial (FIORI, 2006, p.23).

Para Pinto \&Balanco (2013), a década de 2000 foi marcada por vários acontecimentos significativos no plano econômico internacional, podemos ressaltar: a)o significativo crescimento da economia mundial entre 2003 e 2007; b) a crise mundial de 2008; e c) a rápida recuperação da economia mundial amparada na locomotiva chinesa. Podemos destacar como elemento principal desse período o protagonismo desempenhado pela China na dinâmica internacional. De maneira que "essa nova potência em ascensão, inclusive, vem alterando a ordem econômica, política e social vem gerando mudanças na geopolítica internacional e na divisão internacional da produção e do trabalho" ocasionando elevações nos níveis de preços internacionais de commodities, redução nos preços de produtos industrializados e ampliação do consumo de massa em escala mundial (PINTO \& BALANCO, 2013, p. 14).

Sendo assim, o papel desempenhado pela China na economia mundial originou um novo eixo de acumulação, formado pelo EUA exercendo o papel de "consumidor de última instância" do mundo, financiado pelo seu déficit em transações correntes, enquanto a China tornou-se o "principal supridor de bens manufaturados da demanda americana" (PINTO \& BALANCO, 2013, p. 15). De modo que a dinamicidade da indústria chinesa funcionou como uma engrenagem potente de efeitos positivos para outras regiões do mundo, como por exemplo, na Ásia, na América Latina e na Europa.

\section{CONCLUSÃO}

"O longo século $X X$ " - expressão emprestada do título do livro de Arrigui (1996) apresentouduranteseu transcurso histórico, uma sucessão de auges e quedas de hegemonias. Atrelado à esse processo, se evidenciou uma concentração do poder militar, cultural e econômico; que simultaneamenteapresentou uma vultosa capacidade de universalizar a ideologia - e modelo de reprodução do capital- de quem detinha o poder naquele determinado momento histórico. Como, por exemplo, a expansão capitalista da hegemonia britânica com o padrão ouro-libra e a disseminação da globalização/financeirizaçãodo seu forte sucessor, o padrão ouro-dólar/dólar-dólar, capitaneada pela vigente hegemonia americana.

\footnotetext{
${ }^{14}$ Fiori (2006, p. 58) ressalta que "tanto a Alemanha como o Japão nem perderam seu lugar na hierarquia das economias nacionais e nem deixaram de ser países cada vez mais ricos. Apenas não são mais protagonistas, já que perderem a liderança no processo de acumulação do capital em escala global”.
} 
Historicamente, o fim dos Acordos de Bretton Woods, em meados dos anos 1970, representaram a quebra dos cânones keynesianos, abrindo espaço para a promoção de uma nova forma de acumulação e renovação de poder dos capitais norte-americanos por meio do modelo de regulação liberal e da acumulação pela via financeira. Dessa forma, o mundo contemporâneo passa a apresentar uma nova configuração específica do capitalismo, na qual o capital portador de juros está localizado no centro das relações econômicas e sociais. Em que novos fatores penetraram e adquiriram importância na esfera da reprodução do capital. De maneira que o capital busca "se reproduzir", incessantemente, sem sair da esfera financeira, sob a forma de juros de empréstimos, dividendos e outros pagamentos recebidos a títulos de posse de ações e, enfim, de lucros nascidos de especulação bem-sucedida (CHESNAIS, 2005).

É válido ressaltar, que este padrão de reprodução predominante financeiro, está alicerçado numa grande assimetria econômica e social, perpetuando-seno crescente endividamento dos estados nacionais e na sua contínua perda de autonomia diante dos capitais privados internacionais. Dessa forma, este artigo, de maneira deliberada, tem o intuito de mostrar as agruras do funcionamento do atual sistema econômico internacional e, de como esse funcionamento restringe e condena o desenvolvimento econômico da quase totalidade das economias nacionais em prol do crescimento dos capitais privados especulativos alojados no centro das transações econômicas internacionais.

\section{REFERÊNCIAS BIBLIOGRÁFICAS}

ARRIGHI, G. O longo século XX: dinheiro, poder e as origens de nosso tempo. Tradução Vera Ribeiro. Contraponto. São Paulo, 1996.

BALANCO \& PINTO, Eduardo Costa. Os anos dourados do capitalismo: uma tentativa de harmonização entre as classes. PESQUISA \& DEBATE, SP, volume 18, número 1 (31) pp. 27-47, 2007.

CHESNAIS, F. A finança mundializada: raízes sociais e políticas, configuração e consequência. Tradução de Rosa Maria Marques e Paulo Nakatani. São Paulo, Boitempo, 2005.

CANO, W. Soberania e Política Econômica na América Latina. São Paulo. Editora UNESP, 2000.

DATHEIN, R. Sistema monetário internacional e globalização financeira nos sessenta anos de Bretton Woods. Revista da Sociedade brasileira de Economia Política. Rio de Janeiro, nº 16, p. 51-73, junho 2005.

EICHENGREEN, B. A Globalização do Capital - uma história do sistema monetária internacional.Editora 34, 2000.

FANJZYLBER, F. La industrializacion trunca de América latina. México, 1983.

FIORI, J. L. Globalização, hegemonia e império. In TAVARES, M. C \& FIORI, José Luís. Poder e dinheiro: uma economia política da globalização. Petrópolis, Vozes, 1997

Sistema Mundial e América Latina: mudanças e perspectivas. São Paulo, junho, 2006.

MCNALLY, David. Global slump: the economics and politics of crisis and resistance, 2010.

MELLO, G. M. C. Teorias marxistas sobre o capitalismo contemporâneo. Programa de PósGraduação em Sociologia, USP, Tese de Doutoramento, 2012.

PANITCH, L. e GINDIN, S.The Making of Global Capitalism.Verso Books, Londres, 2012. 
PINTO, E.; BALANCO, P. Transformações do capitalismo contemporâneo e os impactos para a América Latina: retrospectivas, mudanças e perspectivas. UFRJ. Textos para discussão, 2013.

PINTO, E. C. O eixo sino-americano e as transformações do sistema mundial: tensões e complementariedades comerciais, produtivas e financeiras. In: Ferreira Leão, R.; Pinto, E.C.; Acioly, L. A China na Nova Configuração Global. Impactos políticos e econômicos, IPEA, 2011.

TAVARES, M. C.; FIORI. J. L. (Des) Ajuste global e modernização conservadora. Rio de Janeiro: Paz e Terra, 1993.

TAVARES, M. C.; FIORI. J. L. A retomada da hegemonia norte-americana. In: Tavares, Maria da Conceição; FIORI, José Luís (orgs.). Poder e dinheiro: uma economia política da globalização. Petrópolis, RJ: Editora Vozes, 1997. 